\title{
Impact of Formative Assessment: Comparative Analysis on the Performance of Bachelor of Science in Education Students
}

\author{
S. D. Thanga Shyla \\ Department of Education, St. Joseph University in Tanzania, Dar es Salaam, United Republic of Tanzania
}

\section{Email address:}

thangashyla@gmail.com

\section{To cite this article:}

S. D. Thanga Shyla. Impact of Formative Assessment: Comparative Analysis on the Performance of Bachelor of Science in Education Students. Science Journal of Education. Special Issue: Science Learning in Higher Education. Vol. 3, No. 4-1, 2015, pp. 5-10. doi: $10.11648 /$ j.sjedu.s.2015030401.12

\begin{abstract}
Education is a process as well as a product. To create good product out of education it must be consistent reconstruction. The aim of education should, educate for vocation, knowledge, culture, with the qualitative process of methodologies. Education must have a good method in its systems, especially teaching and learning, so that effective and desirable end products are evolved. Hence quality improvement in educational methodology, whether in teaching or learning, often comes under the purview of educational character, leisure, spiritualism, individual development, social efficiency, complete living. For building up a new generation of men and women, committed to the process of modernization, an appropriate training and motivation of the individuals is impressive. All this is possible through the medium of sound system of education, which needs a dynamic change. Continuous Assessment Test (CAT) will help the student to improve their cognitive development and confidence.
\end{abstract}

Keywords: Education, Formative Assessment, Continuous Assessment Test

\section{Introduction}

Improving the quality of education depends on first improving the recruitment, training, social status and conditions of work of teachers; they need the appropriate knowledge and skills, personal characteristics, professional prospects and motivation if they are to meet this expectation placed upon them (UNESCO Report, 1996: 141- 142).

Teaching is a complex activity. Teaching teachers is a more complex activity, because it involves individuals who are devoted to teaching at various levels. The importance of teachers in the new century has become all the more viable in case of apposite education for one and all. New perspectives and new designs are perhaps imperative in teaching teachers who would be at the helm of affairs in a classroom where the world comes closest to the learner teachers.

The importance of teacher as an agent of change, promoting understanding and tolerance has never been more obvious than today. The need for change, from narrow nationalism to universalism, from ethic and cultural prejudice to tolerance, understanding and pluralism, from autocracy to democracy in its various manifestations, and from a technologically divided world where high technology is the privilege of the few to a technologically united world, places enormous responsibilities on teachers who participate in the molding of the characters and minds of the new generation.

\section{Significance of the Analysis}

Teaching is not just delivery of the prepared lectures. Teachers claim that they teach knowledge, habits, ideals, skills, manners etc. to the learners. Teachers help the students to adjust themselves to their environment. Teaching is a highly complex occupation, and the complaint about the quality of teaching is not new. It is consistently documented in $20^{\text {th }}$ and $21^{\text {st }}$ centuries. Ineffectiveness and lack of commitment from teachers are some, from the learners of both rural and urban locality. A teacher has to play many roles as manage time, and material, content and learners, and are expert communicators. They communicate with almost all the section of community. More over as instructors, teachers have a number of methods to make learners involve in the content of the curriculum. Cognitive development is very important for student teachers so as to handle the classes 
easy, attain self-confidence, emotional maturity and for integrated personality development. Formative assessment helps the students to attain a level of high performance in the final exams. .

\section{Background of the Analysis}

Teachers add to the cultural and to the economic aspects of the knowledge society. They prepare young people to be active citizens and independent life - long learners and this is crucial for their employment opportunities. Today, the teacher education institutions are faced with the challenge of preparing a new generation of teachers to effectively use the new learning tools in their teaching practices. Just one method of instruction cannot prepare teachers to work effectively for the knowledge society. Instead approaches must be comprehensive, integrated and varied together with the traditional modes of instruction; promising and innovative methods should also be incorporated in teacher education curriculum so as to prepare quality teachers.

The programme of activities and experiences developed by an institution responsible for the preparation and growth of the students preparing themselves for educational work or engaging in the work of the educational profession. As an educator, it is necessary to know the method of assessment is useful to the students or not. So I have decided to done an analysis on the evaluating system.

\section{Importance of Formative Assessment}

Formative assessment is continuous (done throughout the term), and will be based on lateral thinking tests as well as activities such as projects, debates and group discussions. The written tests will fall under Classroom Assessment, and activities under Skill-Based Assessment. There will be six tests for each type, in each subject, and the best four performances will be taken into consideration for the final grade. Teachers implement the feedback, corrective and enrichment process in a variety of ways. Many use short, paper and pencil quizzes as formative assessments to give students feedback on their learning progress. But formative assessment also can take the form of essays, compositions, projects, reports, performance tasks, skill, demonstrations, oral presentations, or any device used to gain evidence on students' learning progress. In essence, teachers adopt the format of their formative assessments to match their instructional goals.

\section{Objectives}

i. To find out and analyze the level of performance in science subjects of the B. Sc. Ed science students with reference to Continuous Assessment Test (CAT) and Model Examinations.

ii. To find out and analyze the level of performance in science subjects such as Mathematics, Computer Science, Physics, Chemistry and Biology of the B. Sc. Ed science students with reference to Continuous Assessment Test (CAT) and Model Examinations.

iii. To find out the significance of CAT exams among B. Sc. Ed science students

\section{Method of Study}

The study was conducted in the Department of Education, St. Joseph University in Tanzania. There were 390 students in the batch in five different branches such as B. Sc. Education with Mathematics, B. Sc. Education with Computer Science, B. Sc. Education with Physics, B. Sc. Education with Chemistry, and B. Sc. Education with Biology. Each branch contains four science modules and each module consists of five units. Each branch was undergone a formative assessment test after regular interval. A summative exam was conducted at the end of the semester. The Summative and formative assessment scores were collected and analyzed.

\section{Analysis of Data}

The analysis of data is an important part of any investigation. The data after collection has to be analyzed in accordance with the outline laid down for that purpose. The analysis was done to find out the Academic performance of student teachers on science subjects through formative and summative assessments. The data collected was analyzed and interpreted by the investigator.

Table 1. Performance of $1^{\text {st }}$ year B. Sc. Education with Mathematics.

\begin{tabular}{|c|c|c|c|c|c|c|}
\hline \multirow[b]{2}{*}{$\mathbf{S} / \mathbf{N}$} & \multirow[b]{2}{*}{ Module Name } & \multicolumn{4}{|c|}{ Formative Assessment } & \multirow{2}{*}{$\begin{array}{l}\text { Summative } \\
\text { Assessment } \\
\end{array}$} \\
\hline & & CAT 1 Average & CAT 2 Average & CAT 3 Average & Best 2 CAT Average & \\
\hline 1 & Introductory Algebra & 58.0 & 72.0 & 65.0 & 65.5 & 60.7 \\
\hline 2 & Trigonometry & 73.6 & 64.0 & 68.8 & 69.5 & 66.8 \\
\hline 3 & Calculus & 83.6 & 79.8 & 77.5 & 73.5 & 62.0 \\
\hline \multirow[t]{2}{*}{4} & Numerical Methods & 68.1 & 62.6 & 70.8 & 69.0 & 54.0 \\
\hline & Average & 70.8 & 69.6 & 70.5 & 69.4 & 61 \\
\hline
\end{tabular}




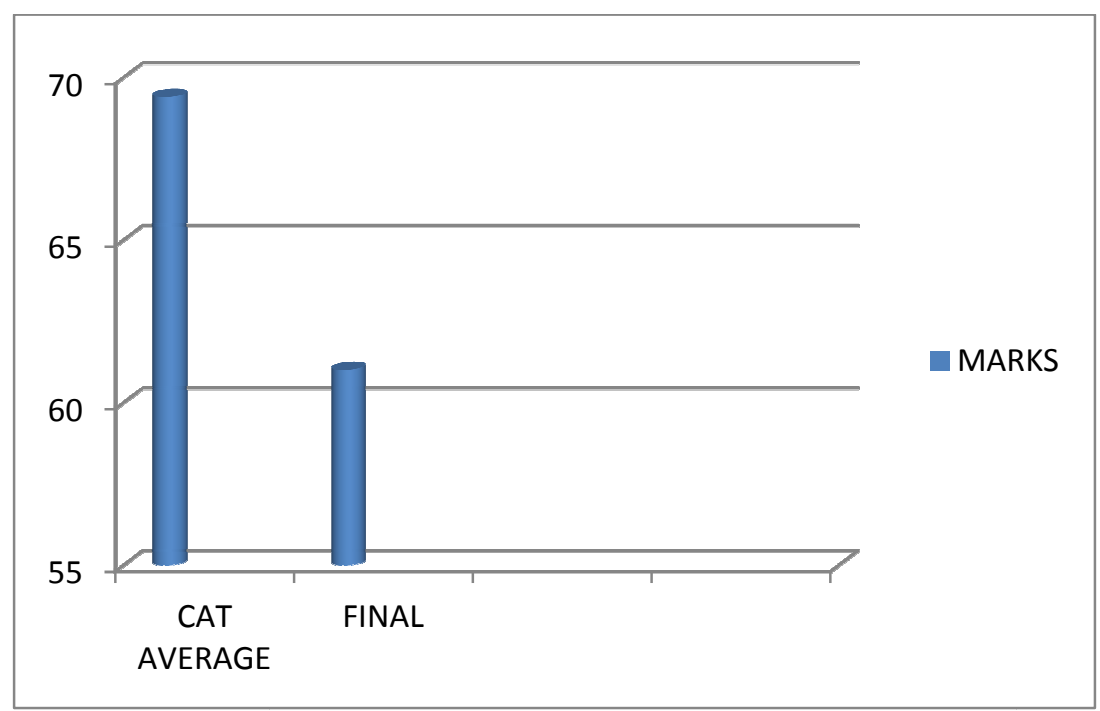

Fig. 1. Performance of $1^{\text {st }}$ year B. Sc. Education with Mathematics

Table 2. Performance of $1^{\text {st }}$ year B. Sc. Education with Computer Science.

\begin{tabular}{lllllll}
\hline & & Formative Assessment & & \\
\hline S/N & Module Name & CAT 1 Average & CAT 2 Average & CAT 3 Average & Best 2 CAT Average & Summative \\
Assessment
\end{tabular}

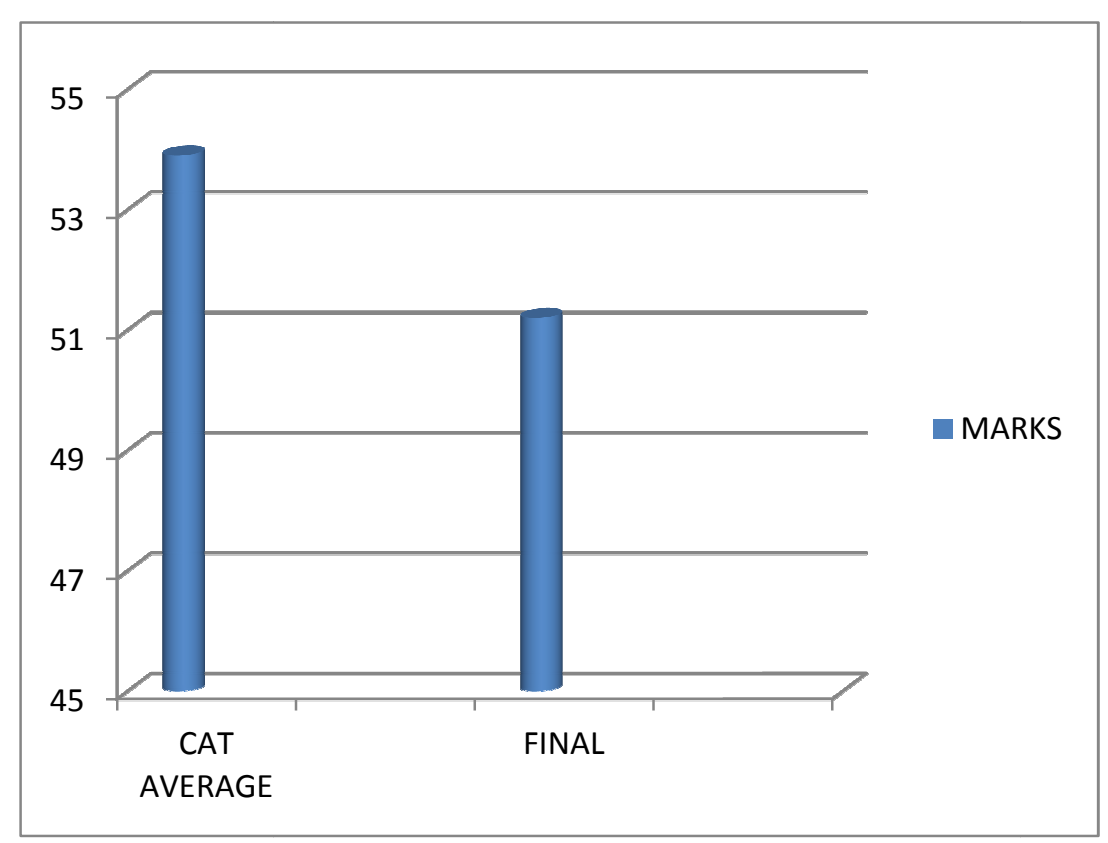

Fig. 2. Performance of $1^{\text {st }}$ year B. Sc. Education with Computer Science

Table 3. Performance of $1^{\text {st }}$ year B. Sc. Education with Physics.

\begin{tabular}{lllllll}
\hline \multicolumn{9}{c}{ Formative Assessment } & & Summative \\
\hline S/N & Module Name & CAT 1 Average & CAT 2 Average & CAT 3 Average & Best 2 CAT Average & Assessment \\
\hline 1 & Mechanics & 61.4 & 66.4 & 50.2 & 63.9 & 61.3 \\
2 & Heat and Thermodynamics & 57.4 & 57.8 & 46.2 & 57.6 & 56.6 \\
3 & Properties of Matter and Sound & 58.4 & 56.8 & 52.2 & 57.6 & 58.0 \\
4 & Optics & 58.0 & 59.6 & 58.8 & 59.2 & 60.0 \\
& Average & 58.8 & 60.2 & 51.9 & 59.6 & 59 \\
\hline
\end{tabular}




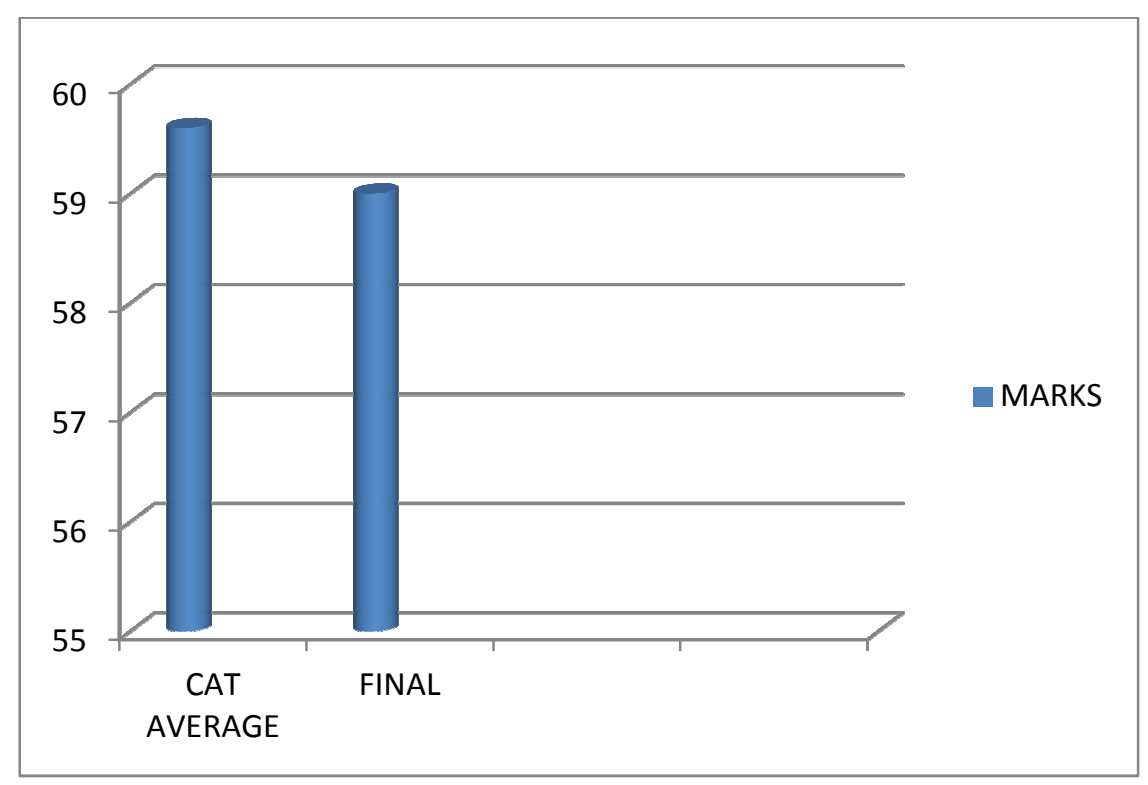

Fig. 3. Performance of $1^{s t}$ year B. Sc. Education with Physics

Table 4. Performance of $1^{\text {st }}$ year B. Sc. Education with Chemistry.

\begin{tabular}{lllllll}
\hline & & Formative Assessment & & Summative \\
S/N & Module Name & CAT 1 & CAT 2 & CAT 3 & Best 2 CAT & Assessment \\
\hline 1 & Analytical Chemistry & 46.0 & 46.2 & 67.0 & 56.6 & 57.1 \\
2 & Concepts In Inorganic Chemistry & 50.2 & 80.0 & 54.0 & 67.0 & 59.3 \\
3 & Hydrocarbons and Stereochemistry & 48.4 & 62.2 & 61.4 & 61.8 & 51.3 \\
4 & Organic Functional Groups & 48.0 & 40.8 & 37.0 & 44.4 & 43.0 \\
& Average & 48.2 & 57.3 & 54.9 & 57.5 & 52.7 \\
\hline
\end{tabular}

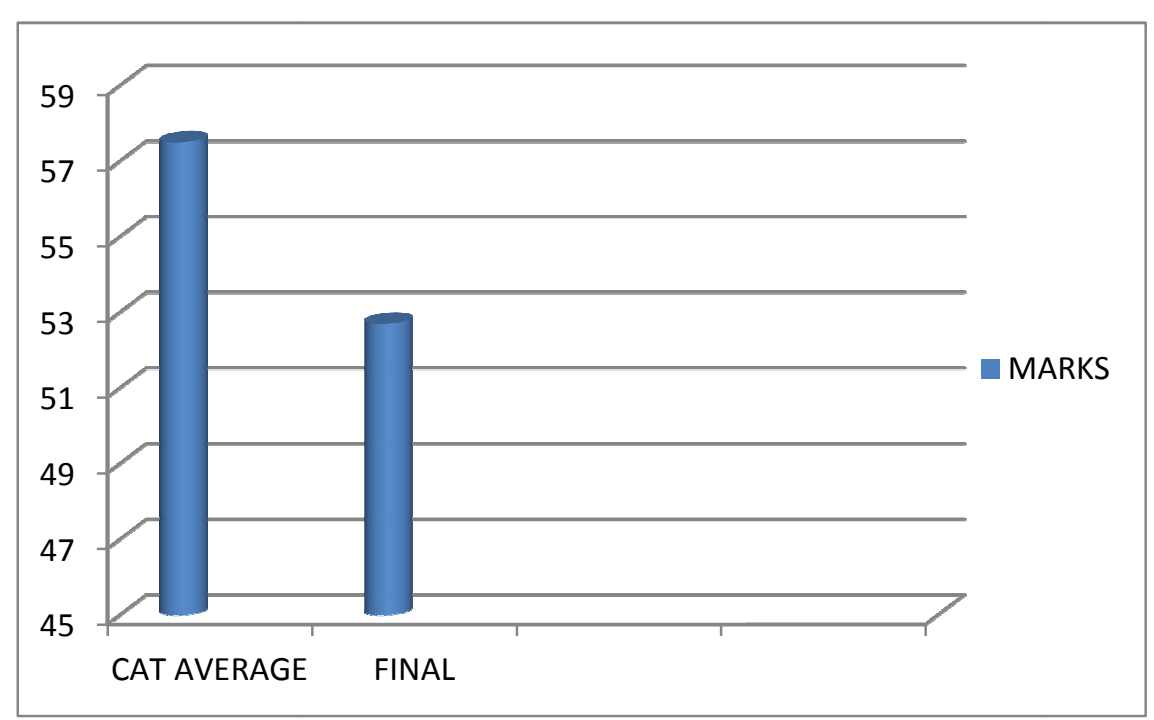

Fig. 4. Performance of $1^{\text {st }}$ year B. Sc. Education with Chemistry.

Table 5. Performance of $1^{\text {st }}$ year B. Sc. Education with Biology.

\begin{tabular}{lllllll}
\hline & & Formative Assessment & & & Summative \\
\hline S/N & Module Name & CAT 1 & CAT 2 & CAT 3 & Best 2 CAT & Assessment \\
\hline 1 & Algae and Bryophytes & 55.0 & 64.2 & 58.8 & 61.5 & 60.9 \\
2 & Fungi, Plant Pathology and Lichens & 64.8 & 62.4 & 60.2 & 63.6 & 60.9 \\
3 & Invertebrate & 49.6 & 65.6 & 66.2 & 65.9 & 72.1 \\
4 & Chordate & 53.8 & 52.0 & 68.4 & 61.1 & 70.7 \\
& Average & 55.8 & 61.1 & 63.4 & 63 & 66.2 \\
\hline
\end{tabular}




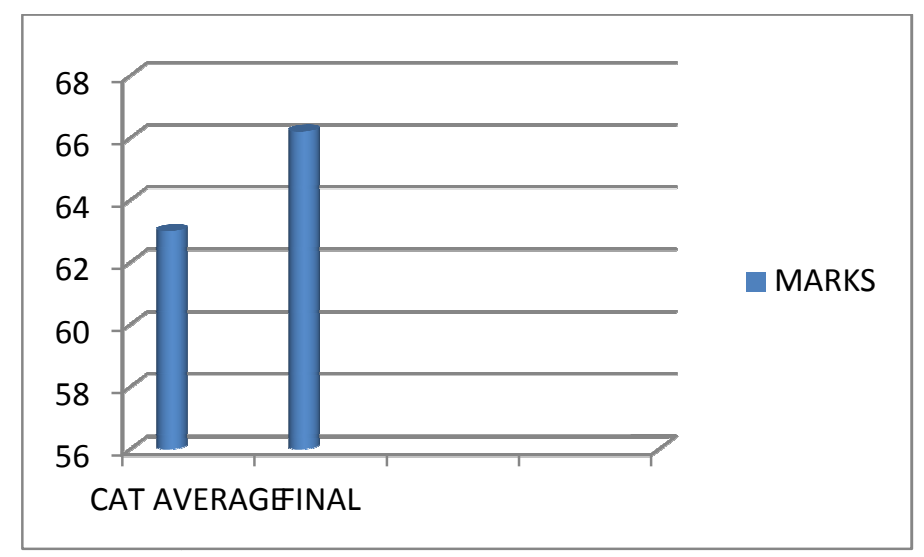

Fig. 5. Performance of $1^{\text {st }}$ year B. Sc. Education with Biology.

Table 6. Final Exam Average.

\begin{tabular}{|c|c|c|c|c|}
\hline Branch & Mathematics & Computer Science & Physics & Chemistry \\
\hline Average & 60.9 & 51.2 & 59 & 52.7 \\
\hline & 20 & $e^{n+y^{s s^{c^{s}}}} c e^{n^{n}}$ & $100^{108}$ & MARKS \\
\hline
\end{tabular}

Fig. 6. Analysis of the Average of Final Exam

\section{Findings, Conclusions and Suggestions}

The purpose of this study was to find out the academic performance of student teachers in science subjects. The CAT exams work very well among B. Sc. Ed science students

(i). The level of performance in science subjects of the B. Sc. Ed science students with reference to CAT and Model Examinations are moderate.

(ii). It was found that there is a significant difference between CAT and model exams with respect to all science subjects.

(iii). The results shows that the CAT exams among B. Sc. Ed science students are significance. It shows impact on the Final exams.

(iv). Analysis of final exam result shows the CAT exams gives more impact on Biology, Mathematics and physics than Chemistry and Computer Science.

\section{Conclusion}

The purpose of this analysis was to find out the academic performance of B. Sc. Ed science students through formative assessment. It was found that the formative assessment gives a great impact on the final exams. Regarding final average, the students from biology scored very high marks than other branches. The teacher of the future must be prepared not only for what is, but also for what is to be. The changes that have occurred are but a prologue to even greater changes in the future. It is indeed a challenging time, but a promising one for the teacher education and for those to devote their life for it.

\section{Acknowledgement}

I thank the administrators of St. Joseph University for all support and guidance to do this analysis successfully. I thank all my colleagues to give moral support and analysis of performance.

\section{References}

[1] Marlow \& Rao, Bhaskara D. (2006). Philosophy and curriculum. New Delhi: Discovery Publishing House. 
[2] Good, Carter V. (1973). Dictionary of education. New York: Mc Graw Hill.

[3] Good, Thomas L. (2008). 21st century education: A reference handbook, Vol 1. New Delhi: A Sage reference publications

[4] Guskey, Thomas R. (1997). Implementing mastery learning (2nd ed.). California, Wadsworth.

[5] Shyla, S. D. Thanga \& Dharma Raja, B. William. (2013). Academic Performance of Pre-service Elementary Teachers in Child Psychology through Computer Supplemented Mastery Learning. Dissertation, Tirunelveli: Manonmaniam Sundaranar University.

[6] Sypher, J. R. (2004). Art of teaching school. New Delhi: Cosmo Publications.

[7] Thomas, H. K., Harrison, F., \& Calkins, N. A. (2005). How to teach. NewDelhi: Cosmo Publications.

[8] UNESCO Report. (1996). Learning: the treasure within. pp: 141- 142
[9] Assessing Your Teaching. Center for Teaching \& Learning Excellence, the University of Utah. Accessed 26 January 2010. http://www.ctle.utah.edu/?\&pageId=2009

[10] Centra, John A. (1993). Reflective faculty evaluation: Enhancing teaching and determining faculty effectiveness. San Francisco: Jossey-Bass.

[11] Chan C.(2010) Assessment: Evaluating your own Teaching, Assessment resources@HKU, University of Hong Kong. Retrieved from http://ar.cetl.hku.hk on 25 September 2014.

[12] Fink, D. L. (1995). Evaluating your own teaching Bolton, MA: Anker Publishing Company Inc.

[13] Seldin, Peter \& Associates. (1990). How administrators can improve teaching: Moving from talk to action. San Francisco: Jossey-Bass.

[14] Seldin, Peter (Ed.), Improving college teaching. Bolton, MA: Anker Publishing Company Inc. 